Article

\title{
Extended Theory of Planned Behavior (ETPB): Investigating Customers' Perception of Restaurants' Sustainability by Testing a Structural Equation Model
}

\author{
Aurelio Tommasetti, Pierpaolo Singer, Orlando Troisi and Gennaro Maione * (D) \\ Department of Business Science-Management \& Innovation Systems, University of Salerno, \\ 84084 Fisciano, Italy; rettore@unisa.it (A.T.); psinger@unisa.it (P.S.); otroisi@unisa.it (O.T.) \\ * Correspondence: gmaione@unisa.it; Tel.: +39-089-96-3087
}

Received: 9 May 2018; Accepted: 18 July 2018; Published: 23 July 2018

check for updates

\begin{abstract}
In the modern competitive scenario, all companies seek to understand how to achieve success. One of the keys to conquer/maintain market shares is sustainability, which is a hot topic of numerous studies that have focused on its use as a solution to obtain social, environmental, economic, and cultural benefits. To this end, the present work aims to identify the variables able to guide consumers towards the choice of sustainable restaurants through the conceptual extension of a theoretical model known in literature as Theory of Planned Behavior (TPB). The authors propose an Extended Theory of Planned Behavior (ETPB), consisting of seven variables: attitude; subjective norm; perceived behavioral control; perceived usefulness; curiosity; behavioral intention; and behavior. The authors used a quantitative approach based on the test of a Structural Equation Model (SEM). Overall, 1023 questionnaires were analyzed. The results of the analysis provided empirical evidence for the hypotheses formulated suggesting that attitude, subjective norm, perceived behavioral control, perceived usefulness, and curiosity affected the consumers' behavioral intention to prefer sustainable restaurants and that behavioral intention affected their actual behavior. Based on what emerged from the analysis, the work could be understood as a useful tool for scholars and practitioners, suggesting interesting theoretical and managerial implications. In fact, on the one hand, it contributes to the enrichment of scientific literature related to the factors triggering human choices, and, on the other, it helps maximize the success of the restaurants by highlighting the levers to be actioned to improve business performances. However, the paper presents a main limit, linkable to the fact that, whilst the use of questionnaires represents an advantage in terms of sample size, on the other hand, it does not allow us to go deeper in understanding the reasons why people prefer restaurants that adopt sustainable practices.
\end{abstract}

Keywords: sustainability; Theory of Planned Behavior (TPB); Extended Theory of Planned Behavior (ETPB); structural equation model (SEM); structural equations modelling

\section{Introduction}

For some years, the growing dynamism and the increasingly fierce competition among companies has pushed scholars and professionals of all disciplines to look for new levers to be used to increase business success. In such a competitive scenario, characterized by high complexity and unpredictable turbulence, in order to survive and develop, companies seek in every way to find the right key for achieving a favorable competitive position on the market, possibly defensible by competitors and able to ensure strategic success [1]. One of the increasingly frequent paths undertaken by companies wishing to conquer/maintain important market shares is sustainability, which is a hot topic of numerous studies that have focused on its use as a solution able to bring social, environmental, economic, and cultural benefits [2]. 
All this is due to the companies' awareness regarding the strong link between sustainability and strategic success to the point of allocating significant investments in that direction, for example, through the employees' sensitization, the adaptation to regulatory developments (increasingly frequent and stringent in last years), the improvement of the products quality, the attention to the image and reputation, the interest in social issues such as the safeguarding of the health of the environment and consumers, and so on. The awareness of the benefits deriving from the pursuit of sustainability has spread in every sector, even in the restaurant one, where companies and consumers are increasingly looking for sustainable practices and behaviors [3].

Not by chance, especially in the last decade, the concept of sustainability has spread on a large scale as a global approach to restaurant management, aimed at both reducing the negative consequences on the environment and at generating socio-economic advantages [4]. To this end, new procedures and cutting-edge technologies have been introduced to significantly increase the benefits obtainable by restaurants that adopt sustainable practices with regard to the quality of raw materials, food safety, reduction of fixed costs through a greater energy efficiency, waste reduction, food recycling, "fair food", and so on. Over the years, the attention paid to sustainability in all its forms has meant that the implementation of sustainable strategies has become a real best practice at the international level [5], as demonstrated by the many projects launched to this end. Some examples are observable in the USA such as the labels "Green Seal GS-46" and "Green Restaurant Certification 4.0 Standards", the ecological initiative of the National Restaurant Association "Conserve Solution for Sustainability", and the guidelines of the "American Beverage Association"; in Europe, the "Nordic Ecolabelling for Restaurants" certification was introduced in 2006 to improve the quality of the restaurant service, and the "State of Sustainability Initiatives" were promoted to provide a point of reference to buyers, producers, policy makers, and consumers in deciding the best way to apply voluntary standards in their decision-making processes in relation to fish products; in the UK, the "Sustainable Restaurant Association" was created to help both restaurant owners and their customers to take on sustainable behavior and the " 50 Best Restaurants Ranking" established a sustainable restaurant award.

However, although the idea of also considering sustainability as a key to strategic success in the restaurant sector is now well established both in the literature and in practice, in fact, our understanding of the reasons leading consumers to prefer a sustainable company still appears unclear and fragmentary.

To this end, the present work aimed to identify the variables that could potentially guide consumers towards the choice of sustainable restaurants through the conceptual extension and the empirical application of a theoretical model known in the literature as the Theory of Planned Behavior (TPB [6]).

To achieve the research objective, the remaining part of the work is structured in six sections. First, it opens with an in-depth examination of the literature concerning the evolution of the studies leading to the birth and the consequent diffusion of the TPB, then describes the role played by sustainability in a business context and in the restaurant sector. Subsequently, the research design is presented with the specification of the methodology used for data analysis, sampling and data collection, hypotheses and modelling, as well as the construct measurement and questionnaire development. Afterwards, the results are first shown and then discussed. Based on what emerged from the analysis, the theoretical and practical implications of the work are debated. Finally, the article concludes by highlighting the limits of the study and ideas for future research.

\section{Theoretical Background}

\subsection{The Birth of the Theory of Planned Behavior}

The consideration of psychological aspects for the prediction and explanation of consumer behavior is not new in the literature. In fact, several authors have addressed and deepened issues related to the psychological component for understanding the factors driving individuals to make their purchasing choices. In this regard, among the most widespread theoretical models, there is the 
Theory of Planned Behavior, introduced by Ajzen [7] (see Figure 1) as a conceptual extension of the Theory of Reasoned Action (TRA) through the consideration of an additional variable, believed to be useful for predicting people's behavior in certain circumstances [8].

In fact, the TRA, previously developed by Ajzen and Fishbein [9], is based on the idea that any human behavior is affected, on the one hand, by the attitude that the person has towards that particular action and towards the outcome that will follow. Attitude is defined as a predisposition to interact in a predictably favorable or unfavorable way with an object, person, or situation. The influence exerted by other people, known as the subjective norm, represents the perception that a given behavior is more or less expected by the persons considered significant for the decision-maker [10].

However, although many empirical studies have shown the existence of a strong ability to explain the attitude and subjective norm to the individuals' behavioral intention [11], in some cases, the consideration of these two variables has not proven to be sufficient for predicting the behavior of human beings. This assumption is based on the TPB [7], which, as previously indicated, contemplates the consideration of a further variable able to contribute to the prediction of the choices that individuals would be willing to carry out. Precisely, this is the perceived behavioral control, understood as the expectation about the ease or difficulty in implementing a certain behavior [12].

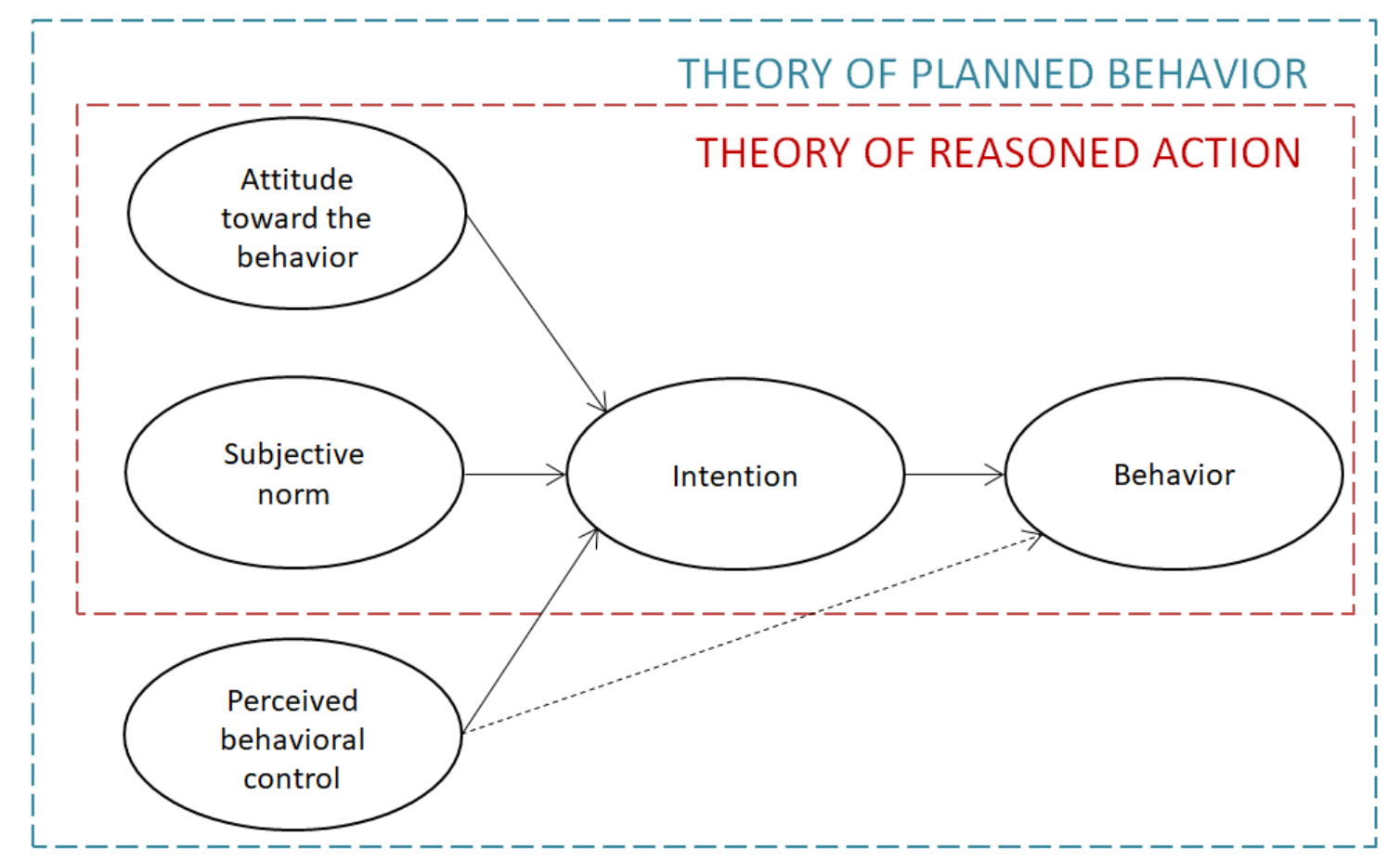

Figure 1. From Theory of Reasoned Action to Theory of Planned Behavior. Source: Source: Adapted from Ajzen [7].

Therefore, the TPB, in addition to what is pursued by the TRA, proposes to predict behavior in situations where the individual does not have complete volitional control as some internal or external barrier is placed in the action [13]: the introduced variable influences both the intention and, separately, the actual behavior. It should be noted that perceived behavioral control can also significantly differ from real behavioral control as it is based on an individual's perception and not on the influence that his/her intention to assume a given behavior actually occurs.

Thanks to the inclusion of an additional variable, the TPB can be applied in many fields of study as well as by virtue of its general connotation that makes it able to adapt from time to time to the different contents in which the analysis is conducted. 
However, although widely used, over the years, the TPB has suffered various criticisms due to its presumed poor predictive efficacy, related, in particular to the use of an insufficient number of variables to explain the reasons pushing individuals to undertake a given behavior in certain circumstances [14-16].

This possible limit has led many scholars to make changes to the original theoretical model by adding to the already contemplated variables ("attitude towards the behavior", "subjective norm", and "perceived behavioral control") as well as other variables such as "perceived ease of use", "personal moral norm", "refusal skill", "perceived moral obligation", "past behavior", "perceived usefulness", and so on.

\subsection{The Rise of Sustainability in the Business Context and in the Restaurant Sector}

Over the past few decades, the idea in which sustainability represents a fundamental lever for business success has received broad consensus and extensive sharing in the literature to the point where many studies have focused on the methods of definition and the implementation of sustainable strategies in companies [17-20].

Overall, in a business context, considerable attention has been paid to the notion of sustainability, which has commonly been expressed as the incorporation of social, environmental, economic, and cultural concerns into the company's strategies [21], an approach capable of producing long run value and opportunities [22].

For some time now, the increasing attention addressing issues linked to sustainability has encouraged companies to become aware of the impact that sustainable strategies can effectively have on business success, to the point of institutionalizing and bureaucratizing the concept of sustainability (for example, by establishing a dedicated unit or division internally).

In fact, until a few years ago, the interest in sustainability had been translated into greater attention to aspects related exclusively to the environment and its protection, with effects of a mostly ethical or, at the most, legal nature: the business world ignored the possible beneficial consequences for consumers and the strategic advantages for companies as a whole. In other words, over the years, sustainability has ceased to be considered as a characteristic merely linked to the environment and has taken on a much wider meaning that involves both social and economic aspects. Currently, there are about three hundred definitions of sustainability, each one with its own expressions, although many of them seem to express identical concepts [23].

To summarize, sustainability, rather than as a characteristic, should be understood as a process based on the protection and enhancement of environmental, economic, and social resources [24]. Precisely, if environmental sustainability can be defined as the ability to guarantee the quality and reproducibility of natural resources, economic and social sustainability are respectively understood as the capacity to generate income and labor for the sustenance of the population and to ensure conditions of human wellbeing (security, health, education, democracy, participation, justice) are equally distributed by class and gender. Strategies able to implement the three capabilities above described are considered sustainable and, therefore, potentially capable of contributing to business success.

The consideration of sustainability as a broad and inclusive process of multiple aspects of a different nature was first reflected in the Brundtland report [25], drawn up by the World Commission on Environment and Development where sustainable development was defined as "a changing process whereby the exploitation of resources, direction of investments, orientation of technological development, and institutional changes are made coherent with future needs, in addition to the current ones. The fulfillment of essential needs requires not only a new era of economic growth for Nations in which the majority of the inhabitants is poor but also the warranty that these poor people have their part of the resources necessary to sustain such a growth".

Over the years, the business world has contributed considerably to facilitate sustainable development; this has been demonstrated, for example, by the high number of theories built in 
relation to the concept of sustainability such as Corporate Social Responsibility, Stakeholder Theory, and Corporate Sustainability [23].

To date, the importance of sustainability is so high that it is a real strategic imperative for 21st century companies that compete in every sector including the restaurant one: the choice of restaurants to follow a sustainable business model derives from a number of political and legislative, social, economic, and reputational conditions [26].

However, despite the tangible benefits resulting from the adoption of sustainable practices, many restaurants continue to encounter resistance, mainly due to the inability of business managers to effectively link sustainability to business [27], for example, by motivating workers, who, whether properly involved, proactively identify, communicate, and pursue opportunities to execute the strategy [28-30].

These difficulties, observable in many contexts, are higher in the food sector, where the growing demand for sustainable restaurants clashes with different aspects that badly conciliate themselves with the desire to operate in compliance with environmental, economic, and social best practices [4]. In order to file these troubles in the restaurant sector, numerous studies have been conducted and many initiatives have been promoted, especially with regard to the development of more effective internal and external communication tools, the efficient use of resources, the assertion of the dictates of a circular economy as well as the introduction of cutting-edge technologies to improve production chains, enhance local production, stimulate increased competitiveness, and promote sustainable restaurant growth. All this, therefore, aims to solve the contradiction that characterizes the restaurant industry, where, on the one hand, some restaurants try to shape their business model on the adoption of sustainable practices as a response to the more conscious consumption of customers, and, on the other, there are restaurants that refuse or do not completely understand the necessity to respond to the needs and expectations of a market that is increasingly attentive to the respect of sustainability in all of its forms [31].

\section{Research Design}

\subsection{Methodology}

To respond to the research objective, the authors used a quantitative approach based on the test of a Structural Equation Model (SEM) able to verify empirically, and above all, simultaneously, the relationships existing between the variables of the proposed model. SEMs are a very common analysis technique in the literature and are often used to test models in different fields of social and behavioral sciences [32].

The adoption of SEMs involves the realization of a series of consecutive and preparatory phases: the specification of the theoretical model to be tested; the parameter estimation and evaluation; and the test of the final model. The development of the phases is iterative in the sense that the sequence has to be repeated several times until the identification of an acceptable model. The objective of the SEMs, as a multivariate statistical analysis technique, is to allow the verification of hypotheses concerning the influence of a set of variables on others [33].

In other words, they enable the study of the linear relations between one or more independent variables and one or more dependent variables, which can be objectively observable or not directly observable and, as such, latent; in this case, these are variables that are measured indirectly through a series of detectable indicators (items). The items coincide with the statements contained in the questionnaire submitted to the respondents.

The choice to employ a modeling based on structural equations and not on linear regressions is very simple: for the study of some phenomena, especially complex ones, it is more appropriate to simultaneously analyze the relationships existing between all the considered variables, being able to obtain, in in this way, better results both in terms of greater accuracy of the estimates and higher parsimony of the model [34]. In other words, the use of this analysis technique is due to 
the consideration that SEM allows the main limitation of regression models to be overcome: the impossibility of simultaneously verifying the causality among several variables.

\subsection{Sampling and Data Collection}

The data were collected by administering questionnaires to a convenience sample: although we did not apply any filters (for example, by gathering answers only from people of a certain age or with specific culinary tastes) that were potentially able to influence the results, we actually did not properly use a specific technique of random sampling (such as simple random sampling, systematic random sampling, stratified random sampling, cluster sampling, and multistage sampling). The questionnaires were administered in five provinces of the Campania region: Naples, Caserta, Avellino, Benevento, and Salerno. To be precise, it is worth highlighting that the questionnaires were administered manually by 10 people (two for each province). This choice may have potentially influenced the composition of the sample. In fact, as per the summary data reported in Table 1, the number of graduates obtained by adding respondents with either a bachelor's degree, master's degree, or other (Ph.D., Master, Professional course, etc.) was 56\%. This percentage was much higher than the average percentage of graduates in Italy, which is around $20.9 \%$ (source: https: / / www.istat.it/it/files//2014/10/ItaliaInCifre2014.pdf). The difference (almost 35\%) between the average national data and the data related to the sample used in terms of education provides evidence that it was a non-probability sample. Therefore, the sampling cannot be considered as random.

Before proceeding to the definitive administration of the questionnaires, the authors carried out a pre-test: to verify the clarity of the questionnaire, it was preliminarily submitted to a small sample of people. The pre-test highlighted the need to make changes to increase the comprehensibility of the questionnaire. Participation in the study was voluntary and absolutely anonymous.

Overall, 1512 questionnaires were effectively distributed. Of these, 1023 were used for the analysis. A total of 489 questionnaires were discarded: 256 for problems related to the response set; and 233 for reasons due to the incompleteness of the answers provided.

Table 1. Respondents' personal features.

\begin{tabular}{cl}
\hline Feature & \multicolumn{1}{c}{ Distribution } \\
\hline \multirow{2}{*}{ Gender } & $54 \%$ Male \\
& $46 \%$ Female \\
\hline \multirow{4}{*}{ Age } & $18 \leq 27 \% \leq 29$ \\
& $30 \leq 39 \% \leq 49$ \\
& $50 \leq 28 \% \leq 69$ \\
& $6 \% \geq 70$ \\
\hline \multirow{5}{*}{ Education } & $1 \%$ Elementary school \\
& $10 \%$ Middle school \\
& $33 \%$ High school \\
& $22 \%$ Bachelor's degree \\
& $26 \%$ Master's degree \\
& $8 \%$ Other (Ph.D., Master, Professional course, etc.) \\
\hline \multirow{5}{*}{ Occupation } & $32 \%$ Employee \\
& $21 \%$ Freelance \\
& $13 \%$ Unemployed \\
& $30 \%$ Student \\
& $4 \%$ Retired \\
\hline \multirow{2}{*}{ Nationality } & $87 \%$ Italian \\
& $13 \%$ Foreign \\
\hline
\end{tabular}

As can be seen from the table, the sample of respondents appears to be rather homogeneous for each of the indicated characteristics, except for nationality, which sees a considerable prevalence of 
Italian people. This datum was quite predictable given that the questionnaires were all administered in Campania, a region of Southern Italy.

The administration was carried out in the period ranging from 3 September 2017 to 27 February 2018. The extrapolated data were analyzed and discussed in March 2018.

\subsection{Hypotheses and Modeling}

In light of the arguments discussed above, the present work aimed to provide an extended interpretation of the model based on the Theory of Planned Behavior (see Figure 2), arriving at the ETPB. To this end, the authors chose to start from the consideration of the variables included in the original theoretical model, i.e., attitude towards the behavior, subjective norm, perceived behavioral control, and behavioral intention.

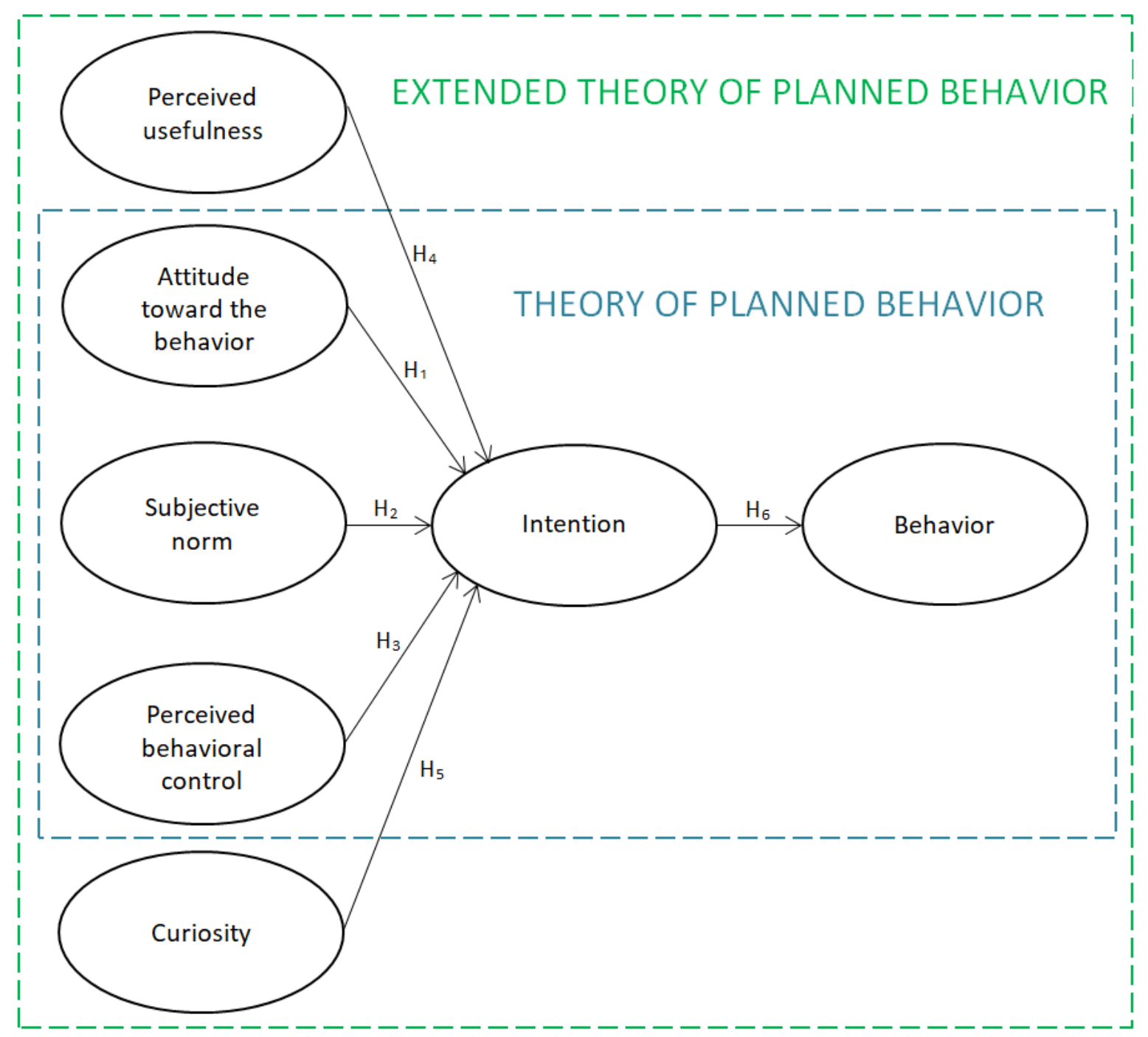

Figure 2. An Extended Theory of Planned Behavior. Source: Authors' elaboration.

It is worth pointing out that although the questionnaire was developed to understand the reasons pushing people to adopt a specific behavior (precisely, the choice of sustainable restaurant), the identification of some effects is actually very difficult. In this regard, as pointed out by Manski [35], there is a reflection problem in identifying the endogenous social effects from observations of the distribution of behavior in a population. To overcome this problem in the present analysis, as suggested by the author (p. 541), a rich and wide collection of data were performed. 
Concerning the hypotheses of the model, attitude is one of the most discussed variables across the field of studies aimed at identifying the reasons why people tend to form certain behavioral intentions. Many scholars have suggested the close correlation between people's behavioral intentions and their attitudes. One of the first authors interested in the topic was Campbell [36], who defined attitude as a sort of behavioral coherence of individuals with respect to social objects. Similarly, Allport [37] considered attitude as a state of mind capable of exercising a direct or indirect influence on the individual's response to all objects and situations with which it is associated. Additionally, Bostrom and Tucker [38] tried to understand the consequences derived from attitudes, arriving at a very broad definition, similar to that done by Rokeach [39], according to whom attitude also includes the concept of beliefs. Fishbein [40], on the other hand, reduced the conceptual scope of attitude, defining it as the predisposition to interface with an object or a class of objects in a favorable or unfavorable way. According to Fishbein and Ajzen [41], attitude regards some social aspects of the individual's world as a person, a physical object, a behavior, or a policy. From this, the idea according to which behavioral intention is a function (also) of attitude towards the behavior has been derived. Based on what is described, it follows that a given behavioral intention can be predicted by analyzing the attitude towards that intention and, hence, that:

\section{Hypothesis 1. Attitude affects behavioral intention.}

Over the years, even the concept of subjective norm has attracted the interest of many authors, although the first studies tended to describe the mechanisms underlying it without highlighting the possible effects on the individuals' behavioral intention. The subjective norm can be defined as the pressure that a group exerts on individuals by altering their perceptions, opinions, attitudes, and behaviors [42]. In other words, it can be expressed as the way in which people's thoughts, feelings, and behavior are influenced by the presence of others [43]. According to Trafimow and Fishbein [44], the subjective norm expresses the result of a series of pressures exerted by some individuals that can influence a person's behavior. Consistently, Ajzen [45] has employed the expression subjective norm to indicate the perception of social pressure able to influence people's behavior. In general, the subjective norm seems to play a fundamental role in the formation of people's behavioral intention with a positive or negative ascendancy that induces each individual to perform certain actions and avoid others. Based on the arguments proposed so far, this analysis intended to check whether:

Hypothesis 2. Subjective norm affects behavioral intention.

Another variable considered capable of affecting an individual's behavioral intention is perceived behavioral control, definable as the set of perceptions related to one's own behavior, determined by the set of accessible control beliefs, i.e., beliefs about the presence of factors that can facilitate or prevent behavioral performance [12]. The conceptualization of perceived behavioral control has been systematically refined since Ajzen [46] introduced it as a key component of the TPB model to indicate the perception of people's ability to control or perform a certain operation or behavior. In fact, very often, people believe that they can perform a certain behavior when they think they have the resources and opportunities to perfect it and think they can freely make the decision to use those resources. Ajzen and Madden [47] have empirically supported the theory by demonstrating how the perceived behavioral control exerts a significant influence on the intention of individuals to assume a given behavior. Hence, the behavioral intention is strongly influenced by the trust that people place in their ability to perform a future action [13]. Therefore, in light of the aforementioned considerations, the present study attempted to understand concretely whether:

Hypothesis 3. Perceived behavioral control affects behavioral intention. 
Perceived usefulness is one of the most important beliefs about product-related attributes that is capable of influencing consumers. In this regard, Davis [48] pointed out that individuals tend to adopt certain behavior on the basis of how much the product (good or service) helps them to perform an activity; whereas the scholar defines perceived usefulness as "the degree to which a person believes that using a particular system would enhance his or her job performance". In this respect, Igbaria et al. [49] suggested that usefulness as an important determinant of any system use. Actually, the significant and great correlation between perceived usefulness and people's behavioral intentions has been stated in many other studies [50-58], which expresses a more or less attitude of the former to affect the latter. In other terms, perceived usefulness is conceived as a determinant of an individual's intention to perform a future behavior. By virtue of what has been debated so far, in this research it could be opportune to verify whether:

\section{Hypothesis 4. Perceived usefulness affects behavioral intention.}

The importance given to curiosity as a variable able to guide the individuals' behavioral intentions is rather dated. In fact, since the end of the XIX century, James [59] developed an entire theory focused on curiosity and its ability to orient human behavior. In the following years, the link between curiosity and behavioral intention has been dealt with in depth by several authors [60-63], all convinced of the high positive correlation between the two variables. In this regard, Spielberger and Starr [64] stressed the fact that curiosity addressed people's future choices to the point where in many circumstances, their behavior could be determined exclusively by their previous curiosity. Therefore, given that curiosity can act as a stimulus for people's willingness to take certain decisions, in the present study, the authors wanted to test whether:

\section{Hypothesis 5. Curiosity affects behavioral intention.}

On the one hand, the literature considers behavioral intention as a variable dependent on many others (such as curiosity, attitude, subjective norm, perceived behavioral control, perceived usefulness, and so forth); on the other hand, it is equally true that it can also be seen as a variable capable of influencing behavior, that is, actions actually taken [65]. According to Triandis and Brislin [66], for example, an individual's behavioral intentions can be seen as self-instructions that enable performing certain behaviors or obtaining particular outcomes. In line with this consideration, Sheeran [67] stated that all theories of attitude-behavior relations converged on the idea that intention was the key determinant of behavior. Consistently, Ajzen [7] underlined that intentions are assumed to capture the motivational factors that influence a behavior. Hence, Ajzen's thought [46] appears to be consistent with the idea according to which, given a sufficient degree of actual control over the behavior, people are expected to carry out their intentions when the opportunity arises. This depends on the strong link from intentions to behavior, thereby behavioral intention acts as the immediate antecedent of behavior. However, some authors (such as Chatzisarantis and Hagger [68]) have suggested that in some circumstances the correlation between behavioral intention and actual behavior is modest or even non-existent. For this reason, the authors have considered it important, with respect to a restaurant's sustainability, to verify whether it is possible to state that:

Hypothesis 6. Behavioral intention affects behavior.

\subsection{Constructs Measurement and Questionnaire Development}

All constructs of the model were measured by using multiple indicators adapted from previous studies.

In particular, the attitude toward behavior was measured by adapting the 4-item scale originally proposed by Taylor and Todd [69] including the following items: "Adopting sustainable practices is 
a good idea"; "Adopting sustainable practices is not a wise idea"; "I like knowing that a restaurant adopts sustainable practices"; and "Restaurants that pursue sustainability adopt appropriate behavior".

The subjective norm was measured by adapting the scale proposed by Venkatesh [55] with the following items: "People who influence my behavior think it is preferable to attend sustainable restaurants"; "People important to me think it is preferable not to go to sustainable restaurants"; "People in my organization (school, university, company, etc.) consider as useless going to sustainable restaurants"; and "In general, people support restaurant sustainability".

Perceived behavioral control was measured by adapting Taylor and Todd's three-item scale [69]: "I would like to attend restaurants that adopt sustainable practices"; "I decide if I go to restaurants that adopt sustainable practices"; and "I think I have the resources, the knowledge and the skills necessary to understand if a restaurant adopts sustainable practices".

To measure perceived usefulness, the 4-item scale developed by Guo et al. [70] was used: "I consider the sustainability of restaurants a useful element for health"; "The sustainability of restaurants does not benefit everyone"; "Sustainability increases restaurant productivity"; and "Sustainability does not improve restaurant performance".

The set of items used to measure the curiosity variable was taken from the Agarwal and Karahanna's study [71]: "Attending sustainable restaurants stimulates my curiosity"; "Attending sustainable restaurants does not make me curious"; and "Attending sustainable restaurants favors my imagination".

Behavioral intention was measured by using the scale proposed by Fu et al. [72]: "I will not recommend attending restaurants that adopt sustainable practices"; "I intend to attend restaurants that adopt sustainable practices in the future"; and "I cannot say positive things about restaurants that adopt sustainable practices".

Finally, to measure the actual behavior, an adaptation of the scale proposed by De Cannière et al. [73] was adopted: "I used to go to sustainable restaurants"; "I spend little time in sustainable restaurants"; and "The number of my visits to sustainable restaurants is low".

The set of items used to measure the various constructs (for convenience, shown in Appendix A) constituted the starting point for the construction of the questionnaire subsequently given to people. The items were ordered randomly to avoid problems linked to the response set. For each item, respondents had the opportunity to indicate how much they agreed with the statements. Specifically, a 5-point Likert scale was used in the questionnaire ranging from 1 (to indicate a strong disagreement) to 5 (to indicate a strong agreement). The choice to resort to a 5-point scale was due to the fact that, in many cases, as demonstrated by Leung's study [74], it had the highest eigenvalue for the factors and the highest cumulative percentages of variations explained.

\section{Findings}

The data emerging from the administration of questionnaires were processed with LISREL 8.80 for Windows, developed by Scientific Software International Inc. in Skokie, Illinois, which is statistical software that enables structural equation modeling for both latent and manifest variables. First, the authors conducted Principal Components Analysis (PCA) to identify the factors best able to explain the chosen constructs.

Next, following the indications of Tavakol and Dennick [75], Tabachnick and Fidell [76], and Pett et al. [77], an iterative process was carried out to verify the validity and reliability of each scale of items obtained after the PCA. Table 2 summarizes the values obtained at the end of the iterative process, highlighting that all of the minimum thresholds of acceptability were exceeded with regard to the KMO Test, the Bartlett sphericity test, the total explained variance of the analyzed phenomenon, and Cronbach's Alpha: 
Table 2. Validity and reliability of the measurement scales.

\begin{tabular}{ccccc}
\hline \multirow{2}{*}{ Variable } & \multicolumn{3}{c}{ Scale Validity } & Scale Reliability \\
\cline { 2 - 5 } & KMO Test & Bartlett Sphericity (sign.) & Total Explained Variance & Cronbach's Alpha \\
\hline Attitude & 0.793 & 0.000 & 69.230 & 0.873 \\
Subjective norm & 0.917 & 0.000 & 77.454 & 0.827 \\
Perceived Behavioral control & 0.855 & 0.000 & 76.856 & 0.934 \\
Perceived usefulness & 0.892 & 0.000 & 78.348 & 0.844 \\
Curiosity & 0.753 & 0.000 & 61.602 & 0.769 \\
Behavioral intention & 0.799 & 0.000 & 66.123 & 0.821 \\
Behavior & 0.854 & 0.000 & 71.325 & 0.812 \\
\hline
\end{tabular}

After verifying the validity and reliability of each scale of items, a structural equation model (SEM) was developed to test the simultaneous existence of causal relationships between the considered variables. In particular, the authors used the maximum likelihood method for the model estimation. Its adaptation goodness, as shown in Table 3, was measured by taking into account the minimum acceptability thresholds of several indices: the ratio between Chi-square and degrees of freedom (X2/df); Incremental Fit Index (IFI); Root Mean Square Error of Approximation (RMSEA); Comparative Fit Index (CFI); and Root Mean Residual (RMR).

Table 3. Absolute and incremental fit indices.

\begin{tabular}{cc}
\hline Fit Indices & Detected Values \\
\hline $\mathrm{X} 2 / \mathrm{df}$ & 2.458 \\
$\mathrm{IFI}$ & 0.972 \\
$\mathrm{RMSEA}=\sqrt{\frac{\left(\mathrm{X}^{2}-\mathrm{df}\right)}{\mathrm{df}(\mathrm{N}-1)}}$ & 0.04 \\
$\mathrm{CFI}=1-\frac{\tau_{\mathrm{k}}}{\tau}$ & 0.988 \\
StdRMR $=[2 \Sigma \mathrm{i} \Sigma \mathrm{J}]\left[\frac{(\mathrm{Sij}-\sigma \mathrm{ij})^{2}}{\mathrm{k}(\mathrm{k}+1)}\right]^{1 / 2}$ & 0.05 \\
\hline
\end{tabular}

Figure 3 provides a graphical representation of the tested SEM, highlighting the intensity of the relationships between the considered variables:

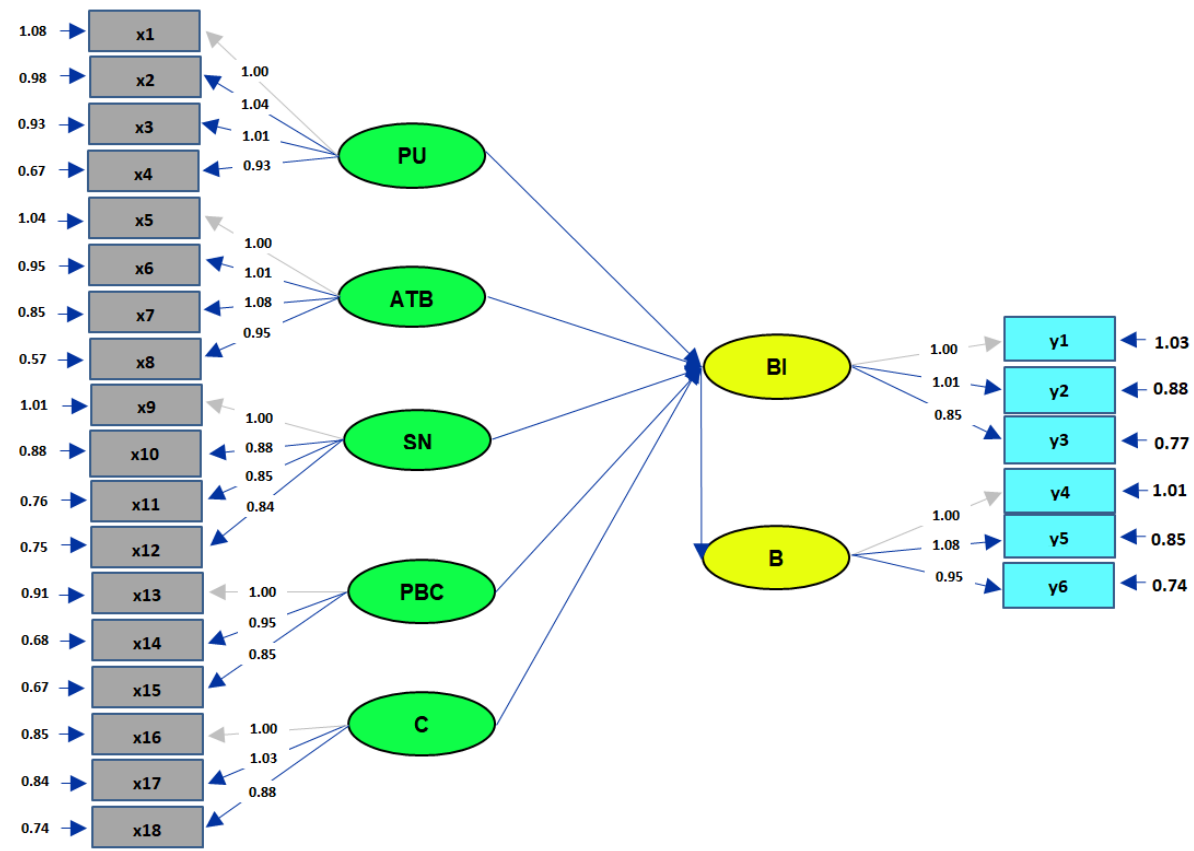

Figure 3. The estimated SEM path model. Source: Authors' elaboration. 
Starting from the early checks carried out, each scale of items was valid, as shown in Table 2 . The fact that the scales were valid means that they were proven to adequately and exhaustively represent the investigated phenomenon. In fact, the findings demonstrated the overcoming of the $\mathrm{KMO}$, highlighting an acceptable deviation between the observed and partial correlations with a good overall sample adequacy. This consideration was justified by Crane et al. [78], according to which, values higher than 0.60 suggested that the factor analysis of the variable was adequate. In accordance with what was written by Tabachnick and Fidell [76], since the significance of all scales was less than 0.005 , the Bartlett Test was also overcome, emphasizing a high homoscedasticity, understood as homogeneity of the variance of the aleatory variables with a normal distribution. Moreover, the validity of the scales was also demonstrated by the fact that each of them presented a total explained variance greater than 0.50, which was in line with that stated by Pett et al. [77].

In addition to being valid, all the scales of items were also reliable since they showed a high degree of internal consistency with Cronbach's Alpha values greater than 0.70 [76]. Subsequently, as shown in Table 3, the fit of the model was evaluated. To this end, more indices were considered. In particular, the authors considered the ratio between Chi-square and degrees of freedom, which should range from 1 to 3 as suggested by Corbetta [79].

Similarly, the RMSEA, which avoids errors due to the size of the sample by taking into account the discrepancy of the hypothesized model, with optimally selected parameter estimates and the population covariance matrix, was satisfied with a value lower than 0.06 [80]. In line with the arguments put forward by $\mathrm{Hu}$ and Bentler [81], one of the main indices capable of testing the fit of a SEM is the CFI, which examines the discrepancy between the data and the hypothesized model overcoming the problems related to the sample size. The CFI was adequate since its value was higher than 0.95. The last index considered was the StdRMR, which measures the discrepancy between the sample covariance and the model covariance matrix. As its value was lower than 0.08 , it can be considered as a good adaptation index of the model.

The graphical representation shown in Figure 3, relating to the estimated SEM, shows a high relational intensity between the variables, demonstrating the solidity of the tested path model.

Finally, Table 4 summarizes the results related to the hypotheses of the model tested.

Table 4. The results related to the hypotheses of the model tested.

\begin{tabular}{lc}
\hline \multicolumn{1}{c}{ Hypothesis } & Result \\
\hline $\mathrm{H}_{1}:$ Attitude affects behavioral intention & Verified \\
$\mathrm{H}_{2}:$ subjective norm affects behavioral intention & Verified \\
$\mathrm{H}_{3}$ : Perceived Behavioral control affects behavioral intention & Verified \\
$\mathrm{H}_{4}$ : Perceived usefulness affects behavioral intention & Verified \\
$\mathrm{H}_{5}:$ Curiosity affects behavioral intention & Verified \\
$\mathrm{H}_{6}$ : Behavioral intention affects behavior & Verified \\
\hline
\end{tabular}

\section{Discussion}

The results of the work provide empirical evidence on the hypotheses formulated.

Starting from the first hypothesis, what clearly emerged was the fact that people turned to restaurants that adopted sustainable practices as they believed that sustainability entailed a usefulness: those that sought features of sustainability in the choice made by restaurants related to food safety, reduction of fixed costs through a greater energy efficiency, waste reduction, food recycling, "right food", etc. believed that this set of elements was useful for them and for everyone else. In this sense, this finding was consistent with Ma et al. [82], according to whom the usefulness generated by the adoption of sustainable practices produces positive impacts that spill over into the environmental dimension as well as the social and economic sphere.

However, as suggested by the results of the analysis, to direct consumers towards sustainable restaurants, it is necessary that they have a certain attitude to do so, otherwise all efforts could 
be useless or even harmful. In fact, as stated by Vermeir and Verbeke [83], even if the interest in sustainability increased and the consumer attitudes were mainly positive, behavioral patterns are not always univocally consistent with attitudes. In any case, relying on a favorable attitude to choose a sustainable restaurant is a good starting point to stimulate consumers and companies into adopting strategies aimed at sustainability in all forms. The positive correlation that emerged from the analysis appeared coherent with other studies dedicated to the incidence of attitudes towards sustainability and sustainable consumption behavior [84-86]. However, very often, attitude alone is not enough to explain consumer behavior and also exists in the restaurant sector. Therefore, other determinants have to be considered including the subjective norm.

This variable is decisive in many circumstances including the context of sustainable restaurants as highlighted by the study. This statement is in line with Barr's considerations [87], according to which, many individuals, especially when they are in uncertain or ambiguous situations (for example, when they have insufficient information on the subject), tend to put in place a behavior oriented to sustainability. This result suggests that, consistently with what stated by Fielding et al. [88], consumers' sustainable choices also depend on variables that go beyond their personal sphere, given that their behavioral intention appears to be strongly influenced by their tendency to conform their opinions and behaviors to the way they act and think of the reference people. In this regard, Glanz et al. [89] and Robinson and Smith [90] stated that the subjective norm was one of the variables mostly able to predict the purchase intentions of sustainable products.

According to the analysis, perceived behavioral control also plays a decisive role in shaping the behavioral intention of consumers who are attentive to the sustainability of their restaurants. In fact, like the other variables, perceived behavioral control exerts a force that is able to orient consumers towards the choice of a restaurant adopting sustainability practices. This result was in line with the studies conducted by Vermeir and Verbeke [83], who perceived that behavioral control represented how much a person thought it is easy or difficult to purchase a product made by following environmental, social, and economic sustainability, due to a series of reasons that can make the purchase decision articulated and complex: in many circumstances, the consumer has no intention of choosing sustainable restaurants if he/she does not feel able to achieve the desired result. In this regard, among the main reasons impeding the choice of sustainable restaurants, it is plausible to suppose that there is information asymmetry regarding the strategies implemented by the company. In other words, in the restaurant sector, the main factor that consumers perceive they have poor behavioral control over is the lack of information concerning the ways in which the sustainable restaurant acts.

Another variable apparently capable of positively influencing the behavioral intention of consumers of sustainable restaurants is curiosity. In support of this finding, Kashdan and Steger [91] defined curiosity as one of the main ingredients of the "sustainability of well-being in everyday life, an appetitive state involving the recognition, pursuit, and intense desire to investigate novel information and experiences that demand one's attention development of well-being and meaning in life: it contributes to the development and sustainability of meaningful living". Likewise, Clark [92] stated that "just as sustainability science has reached out to contribute to and learn from the world of applied problem-solving, so has it remained closely linked with curiosity-driven research across a range of disciplines". These considerations contribute to corroborate what emerged from the analysis, i.e., that in the restaurant sector, between people's curiosity and their behavioral intention, a positive correlation exists and is strong.

Finally, as easily predicted, the correlation between behavioral intention and actual behavior also emerged from the study. In reality, this result seems to be the almost obvious, whether one thinks of the high number of studies that have shown the remarkable explanatory capacity of behavioral intentions on actual behavior in several sectors. In this regard, Tapia-Fonllem et al. [93] suggested that in relation to sustainability, consumers tended to show a certain consistency between the choices they intended to make and those that they actually carried out. Coherently, Kim et al. [94] identified behavioral intention as the variable that best explained the effective sustainable behavior of consumers: 
the greater their intention to adopt sustainable practices, the greater the probability that they will prefer restaurants implementing strategies based on environmental, social, and economic sustainability.

In light of what has been discussed so far, it is possible to believe that the work offers food for thought under a double profile, theoretical and practical, as discussed in the following paragraph.

\section{Implications}

\subsection{Theoretical Contribution}

The results that emerged from the analysis led to us consider the work as a potentially useful tool for both scholars and practitioners, being able to suggest interesting theoretical and managerial implications.

First, the study could be useful for all those who study people's behavior and, more particularly, consumer behavior, as it contributes to the enrichment of scientific literature related to the factors triggering human choices. Specifically, all the hypotheses originally formulated appeared satisfied, highlighting the ability of the variables taken into consideration to have a significant impact on the formation of consumer choices. Precisely, starting from the consideration of the classical variables adopted in the Theory of Planned Behavior, the analysis confirmed the incidence of attitude, subjective norm, and perceived behavioral control on people's behavioral intention, which, in turn, was able to influence the behavior actually adopted in the restaurant sector. This corroborated the solidity of the theoretical model developed by Ajzen [7], like many other studies in the literature.

However, in addition, the work proposed an extension of the TPB by introducing two further variables, perceived usefulness and curiosity, thus formulating the ETPB. The two further variables were also able to influence behavioral intention and indirectly, the consumers' behavior aimed at choosing restaurants adopting strategies based on environmental, social, and economic sustainability, highlighting that simply considering the classical variables of TPB could be reductive, at least in that sector. In fact, the fact that behavioral intention and consumer behavior are influenced by further variables suggests to scholars the importance of not being limited to the application of the TPB for the analysis of the phenomena conditioning the choice of restaurants, but to propose on the basis of what has been indicated by previous studies, new and broader conceptualizations.

This model, in fact, represents a possible theoretical development capable of identifying, with a sufficient degree of approximation, the variables able to influence consumer behavior in the restaurant sector. This ETPB, therefore, fits into the literature as a stimulus to the formulation of other conceptual models capable of providing their contribution to the change of perspective in scientific research regarding consumer choices. In this sense, the work is proposed as a possible assumption to guide future research on behavioral marketing by shifting the focus from traditional theoretical models to innovative ones, inclusive of additional variables whose importance has emerged during the years.

The study also highlighted the need to deepen the issues related to sustainability and the benefits that it could bring to consumers, companies and, more in general, the whole community $[94,95]$. In fact, although sustainability is a topic widely debated in the literature, with regard to the restaurant industry, it still seems to be at a primordial stage. For this reason, the work could contribute to a deeper understanding of the benefits obtained from the pursuit of sustainable behavior. To this end, further analysis in the restaurant sector could be conducted to provide empirical feedback through results that are comparable synchronically and diachronically. The greater attention of the academic world towards sustainability could prove useful, especially in terms of deepening the issues connected to sustainability and also acting as a starting point for penetrating diffusion in company practice. In this sense, studies similar to the conducted one could help raise awareness on the importance of providing theoretical advances regarding economic, social, and environmental sustainability in the restaurant sector, in particular, but also more generally in other sectors. Conducting further studies in this direction would mean identifying other aspects taken into consideration by customers of 
sustainable restaurants and could help build a solid base for both the expansion of the state of the art and for strengthening beliefs on the importance of adopting sustainable practices in every sector.

\subsection{Managerial Insights}

As previously mentioned, the proposed model can also provide managerial insights. In fact, it offers empirical evidence of the variables that determine and sometimes condition consumer behavioral intention, showing themselves to be capable of clearly impacting their future restaurant choices. Concretely, this work can be considered as instrumental to the assumption of decisions able to maximize the success of restaurants that pursue the path of sustainability, helping to strengthen the awareness of possible levers that could be activated to achieve a significant improvement in company performance.

In this regard, it worth underlining the advantage that those who manage a sustainable restaurant could derive from the consideration of the results derived from a structured empirical analysis, taking into account several factors potentially able to affect behavioral intentions and actual consumer behavior.

This observation highlights the potential usefulness of the work, opportunely employable by managers and entrepreneurs who want to understand consumer behavior and the reasons behind why certain purchasing choices are made, especially in the context of the restaurant industry. Understanding the reasons behind consumer behavior allows businesses to anticipate future trends, ensuring the availability of more time to define and then implement strategies capable of intercepting their needs and, therefore, attract them.

In fact, anyone who owns the property or manages a restaurant could benefit by following a strategic path based on sustainability in terms of greater business profitability. In this regard, the work emphasized that the consumers' choice to choose a restaurant that adopted sustainable practices was not accidental, but, on the contrary, was determined by variables that are clearly identifiable and hence governable.

However, the implementation of sustainable strategies requires the preventive and adequate management of consumer behavioral levers. In this regard, as suggested by the results of the analysis, much attention should be paid to various variables including attitude. To this end, it is necessary to stimulate the restaurant customers' mental state, trying to act on their predisposition towards choosing what is sustainable, leading them to believe that the choice would be consistent with their way of thinking. Furthermore, strategies aimed at attracting and retaining customers towards sustainable restaurants cannot ignore the subjective norm. In other words, they have to take into consideration the direct or indirect influence that each individual may deal with from other people (relatives, friends, colleagues, etc.) regarding the choice of restaurant to have lunch or dinner. Therefore, restaurants that intend to make sustainability the key to their success, in addition to paying attention to the consumer, should turn their interest to the target group with whom the consumer relates. One way to do this could be, for example, offering discounts for large groups of people or those who go to the restaurant with their family members.

Another variable to which a restaurant's management should pay attention is perceived behavioral control, since it has been proven to be capable of influencing an individual's behavioral intention: people tend to choose what they think they can control by having the necessary resources. In other words, it might be advantageous making people think that they have all the resources they need to get to a restaurant that adopts sustainable practices. For example, to attract people who do not like long waiting times, those who manage a sustainable restaurant could focus on the speed of the offer to show the rapidity of the service.

In the same way, it should be made clear that going to a sustainable restaurant is useful from many perspectives since this choice can provide concrete benefits to consumers in social, environmental, and economic terms. For example, in the case of people who are attentive to the protection of the environment, company management could implement strategies based on the use-inside and outside 
the restaurant-of an energy-saving lighting system, or on the use of ovens fueled by electricity or pellets rather than wood, and so on.

Equally fruitful in terms of business success, this could be defined as business strategies aimed at stimulating restaurant customers' curiosity, considered able to guide their behavioral intentions and, therefore, their actual behavior: for a restaurant (but not only), arousing the curiosity of individuals is the first step to "convert" their status from potential consumers to actual customers, paving the way in which other variables can be leveraged to try to attract and retain them over time.

\section{Conclusions}

This study offered interesting ideas on which policy makers should reflect. In this sense, this work also contributes to the dissemination of the culture of sustainability in terms of government choices to be taken to ensure that the results obtained by single restaurants are replicable for the benefit of the entire sector. In particular, it would be useful for policy makers, in addition to scholars and managers, to define and implement policies by taking into account the actual determinants of consumer behavior. The starting point on which to build government policies capable of maximizing the benefits generated by the adoption of sustainable behaviors could also be different from the TPB, provided that there is a rigorous foundation in the literature dedicated to the topic and in operational practice.

Developing government policies focused on theoretical models demonstrated from both a theoretical and empirical point of view such as the ETPB tested in the present study, means defining strategies of environmental, economic, and social policy around a sufficiently solid theoretical-practical framework. Naturally, this should not lead us to believe that implementing strategies based on already tested theoretical-practical models will certainly lead to positive results, but, at least suggests that there is a greater probability of success.

In this regard, in the present case, understanding the reasons why consumers assume a certain behavior makes it possible to predict their expectations and better interpret their needs, thus avoiding making mistakes based on merely theoretical models that do not lend well to act as a starting point.

Furthermore, testing the structural equation model makes it possible to state that all the formulated hypotheses were demonstrated, namely that the identified variables were actually able to direct consumer behavior towards the choice of a sustainable restaurant. This produced a significant impact. First, it can be usefully considered by scholars of human behavior as a pioneer approach for the development of new theoretical models to enrich the scientific literature with concepts that are better able to meet the cognitive needs necessary to provide suggestions that can be transformed into concrete strategies.

Furthermore, the work can act as an incentive for practitioners of the restaurant sector to no longer consider sustainability as an abstract goal to be pursued, but as the key to business success, achievable through the careful management of the levers identified as capable of conditioning consumer behavior.

The fact that the theoretical model has been empirically tested by administering more than 1000 questionnaires makes the results rather generalizable.

Ultimately, it is worth highlighting that, as in any kind of research, even this work had limitations. Precisely, whilst the use of questionnaires represented an advantage in terms of sample size, on the other hand, it did not allow going deeper in understanding the reasons why people preferred restaurants that had adopted sustainable practices. To overcome this limit, it may be appropriate in the future to carry out further analysis, possibly by engaging a qualitative technique (such as in-depth interviews) to verify whether the results obtainable are homogeneous with respect to those that emerged from the present quantitative analysis.

Author Contributions: The work is the result of all the authors' synergistic contribution. However, each author has dealt with some paragraphs more than others. More in detail: A.T. has written Section 1; G.M. has realized Sections 2.1, 3.2, 3.4, 5 and 6.2; P.S. has dealt with Section 7; O.T. has elaborated Sections 2.2, 3.1, 3.3, 4 and 6.1.

Funding: This research received no external funding.

Conflicts of Interest: The authors declare no conflict of interest. 


\section{Appendix A. Constructs, items and sources}

\begin{tabular}{|c|c|c|}
\hline Variable & Items & Source \\
\hline Attitude & $\begin{array}{l}\text { - } \quad \text { Adopting sustainable practices is a good idea. } \\
\text { - } \\
\text { Adopting sustainable practices is not } \\
\text { a wise idea. } \\
\text { I like knowing that a restaurant adopts } \\
\text { sustainable practices. } \\
\text { - } \quad \begin{array}{l}\text { Restaurants that pursue sustainability adopt } \\
\text { appropriate behavior. }\end{array}\end{array}$ & Taylor and Todd [69] \\
\hline Subjective norm & $\begin{array}{l}\text { - People who influence my behavior think it is } \\
\text { preferable to attend sustainable restaurants. } \\
\text { People important to me think it is preferable } \\
\text { not to go to sustainable restaurants. } \\
\text { People in my organization (school, university, } \\
\text { company, etc.) consider as useless going to } \\
\text { sustainable restaurants. } \\
\text { In general, people support } \\
\text { restaurant sustainability. }\end{array}$ & Venkatesh [55] \\
\hline Perceived Behavioral control & $\begin{array}{l}\text { - } \quad \text { would like to attend restaurants that adopt } \\
\text { sustainable practices. } \\
\text { - } \\
\text { I decide if I go to restaurants that adopt } \\
\text { sustainable practices. } \\
\text { I think I have the resources, the knowledge and } \\
\text { the skills necessary to understand if } \\
\text { a restaurant adopts sustainable practices. }\end{array}$ & Taylor and Todd [69] \\
\hline Perceived usefulness & $\begin{array}{l}\text { - } \quad \text { consider the sustainability of restaurants } \\
\text { a useful element for health. } \\
\text { - } \quad \text { The sustainability of restaurants does not } \\
\text { benefit everyone. } \\
\text { - } \quad \text { Sustainability increases restaurant productivity. } \\
\text { - } \quad \text { Sustainability does not improve } \\
\text { restaurant performance. }\end{array}$ & Guo et al. [70] \\
\hline Curiosity & $\begin{array}{l}\text { - Attending sustainable restaurants stimulates } \\
\text { my curiosity. } \\
\text { - Attending sustainable restaurants does not } \\
\text { make me curious. } \\
\text { - Attending sustainable restaurants favors } \\
\text { my imagination. }\end{array}$ & Agarwal and Karahanna [71] \\
\hline Behavioral intention & $\begin{array}{l}\text { - I will not recommend attending restaurants } \\
\text { that adopt sustainable practices. } \\
\text { I intend to attend restaurants that adopt } \\
\text { sustainable practices in the future. } \\
\text { I cannot say positive things about restaurants } \\
\text { that adopt sustainable practices. }\end{array}$ & Fu et al. [72] \\
\hline Behavior & $\begin{array}{ll}\text { - } & \text { I use to go to sustainable restaurants. } \\
\text { - } & \text { I spend little time in sustainable restaurants. } \\
\text { - } & \text { The number of my visits to sustainable } \\
\text { restaurants is low. }\end{array}$ & De Cannière et al. [73] \\
\hline
\end{tabular}

\section{References}

1. Dunning, J.H. The Globalization of Business (Routledge Revivals): The Challenge of the 1990s; Routledge: London, UK, 2014; ISBN 978-1138820715.

2. Saviano, M.; Barile, S.; Spohrer, J.C.; Caputo, F. A service research contribution to the global challenge of sustainability. J. Serv. Theory Pract. 2017, 27, 951-976. [CrossRef]

3. Stubbs, W.; Cocklin, C. Conceptualizing a "sustainability business model". Organ. Environ. 2008, 21, $103-127$. [CrossRef] 
4. Revell, A.; Blackburn, R. The business case for sustainability? An examination of small firms in the UK's construction and restaurant sectors. Bus. Strategy Environ. 2007, 16, 404-420. [CrossRef]

5. Yu, Y.S.; Luo, M.; Zhu, D.H. The Effect of Quality Attributes on Visiting Consumers' Patronage Intentions of Green Restaurants. Sustainability 2018, 10, 1187-1201. [CrossRef]

6. Ajzen, I. Nature and operation of attitudes. Annu. Rev. Psychol. 2001, 52, 27-58. [CrossRef] [PubMed]

7. Ajzen, I. The theory of planned behavior. Organ. Behav. Hum. Decis. Process. 1991, 50, 179-211. [CrossRef]

8. Ajzen, I. Attitudes, Personality and Behavior; Dorsey: Chicago, IL, USA, 1988; ISBN 978-0335217038.

9. Ajzen, I.; Fishbein, M. Attitude-behavior relations: A theoretical analysis and review of empirical research. Psychol. Bull. 1977, 84, 888-918. [CrossRef]

10. Fishbein, M. The relationship between beliefs, attitudes, and behavior. In Cognitive Consistency; Feldman, S., Ed.; Academic Press: New York, NY, USA, 1966; ISBN 978-1483251530.

11. Armitage, C.J.; Conner, M. Efficacy of the theory of planned behaviour: A meta-analytic review. Br. J. Soc. Psychol. 2001, 40, 471-499. [CrossRef] [PubMed]

12. Ajzen, I. Perceived behavioral control, self-efficacy, locus of control, and the theory of planned behavior. J. Appl. Soc. Psychol. 2002, 32, 665-683. [CrossRef]

13. Madden, T.J.; Ellen, P.S.; Ajzen, I. A comparison of the theory of planned behavior and the theory of reasoned action. Personal. Soc. Psychol. Bull. 1992, 18, 3-9. [CrossRef]

14. Teo, T.; Zhou, M.; Noyes, J. Teachers and technology: Development of an extended theory of planned behavior. Educ. Technol. Res. Dev. 2016, 64, 1033-1052. [CrossRef]

15. Wang, S.; Fan, J.; Zhao, D.; Yang, S.; Fu, Y. Predicting consumers' intention to adopt hybrid electric vehicles: Using an extended version of the theory of planned behavior model. Transportation 2016, 43, 123-143. [CrossRef]

16. Karimy, M.; Zareban, I.; Araban, M.; Montazeri, A. An extended theory of planned behavior (TPB) used to predict smoking behavior among a sample of Iranian medical students. Int. J. High Risk Behav. Addict. 2015, 4. [CrossRef] [PubMed]

17. Barile, S.; Saviano, M.; Polese, F.; Di Nauta, P. Il rapporto impresa-territorio tra efficienza locale, efficacia di contesto e sostenibilità ambientale. Sinergie J. Ital. Manag. 2013, 90, 25-49.

18. Polese, F. Local government and networking trends supporting sustainable tourism: Some empirical evidences. In Cultural Tourism and Sustainable Local Development; Fusco, G.L., Nijkamp, N., Eds.; Ashgate: London, UK, 2016; pp. 131-148. ISBN 978-1138253681.

19. Ciasullo, M.V.; Maione, G.; Torre, C.; Troisi, O. What about Sustainability? An Empirical Analysis of Consumers' Purchasing Behavior in Fashion Context. Sustainability 2017, 9, 1617-1635. [CrossRef]

20. Ciasullo, M.V.; Troisi, O. Sustainable value creation in SMEs: A case study. TQM J. 2013, 25, 44-61. [CrossRef]

21. Galpin, T.; Lee Whittington, J. Sustainability leadership: From strategy to results. J. Bus. Strategy 2012, 33, 40-48. [CrossRef]

22. Mandelbaum, D.G. Corporate sustainability strategies. Temple J. Sci. Technol. Environ. Law 2007, 26, 27-42.

23. Chang, R.D.; Zuo, J.; Zhao, Z.Y.; Zillante, G.; Gan, X.L.; Soebarto, V. Evolving theories of sustainability and firms: History, future directions and implications for renewable energy research. Renew. Sustain. Energy Rev. 2017, 72, 48-56. [CrossRef]

24. Baratta, R.; Ugolini, M.M.; Cassia, F. Why should hotels turn green? Exploring emergent sustainable behaviors on lake Garda. In Proceedings of the Toulon-Verona Conference "Excellence in Services", Huelva, Spain, 5 September 2016.

25. Brundtland, G.H. Report of the World Commission on Environment and Development: "Our Common Future"; Oxford University Press: Oxford, UK, 1987.

26. Brown, A.; Schultz, D.; Baccarani, C.; Golinelli, G.M.; Gatti, C.; Volpe, L. Sustainability, Stakeholders and Business Editorial. Sinergie J. Ital. Manag. 2015, 1, 9-15.

27. Porter, M.E.; Kramer, M.R. Strategy \& Society. Harv. Bus. Rev. 2006, 84, 78-92. [PubMed]

28. Lacy, P.; Arnott, J.; Lowitt, E. The challenge of integrating sustainability into talent and organization strategies: Investing in the knowledge, skills and attitudes to achieve high performance. Corp. Gov. Int. J. Bus. Soc. 2009, 9, 484-494. [CrossRef]

29. Hargett, T.R.; Williams, M.F. Wilh. Wilhelmsen Shipping Company: Moving from CSR tradition to CSR leadership. Corp. Gov. Int. J. Bus. Soc. 2009, 9, 73-82. [CrossRef] 
30. Quinn, L.; Dalton, M. Leading for sustainability: Implementing the tasks of leadership. Corp. Gov. Int. J. Bus. Soc. 2009, 9, 21-38. [CrossRef]

31. Napolitano, M.R. Resource Based View e Successo Competitivo. Il caso Bulgari. Econ. Manag. 2000, 3, 69-84.

32. Ullman, J.B.; Bentler, P.M. Structural equation modeling. In Handbook of Psychology: Research Methods in Psychology; Schinka, J.A., Velicer, W.F., Weiner, I.B., Eds.; John Wiley \& Sons: Hoboken, NJ, USA, 2003; pp. 661-690. ISBN 9780471264385.

33. Jais, S.D. Successful Use of Information in Multinational Companies: An Exploratory Study of Individual Outcomes and the Influence of National Culture; Springer: Berlin, Germany, 2007; ISBN 978-3835005358.

34. Gefen, D.; Straub, D.; Boudreau, M.C. Structural equation modeling and regression: Guidelines for research practice. Commun. Assoc. Inf. Syst. 2000, 4, 7.

35. Manski, C.F. Identification of endogenous social effects: The reflection problem. Rev. Econ. Stud. 1993, 60, 531-542. [CrossRef]

36. Campbell, D.T. The Generality of a Social Attitude; University of California: Berkeley, CA, USA, 1947.

37. Allport, G.W. Attitudes in Attitude Theory and Measurement; John Willey Sons: New York, NY, USA, 1967; ISBN 978-0471260554.

38. Bostrom, R.N.; Tucker, R.K. Evidence, personality, and attitude change. Commun. Monogr. 1969, 36, $22-27$. [CrossRef]

39. Rokeach, M. A theory of organization and change within value-attitude systems. J. Soc. Issues 1968, 24, 13-33. [CrossRef]

40. Fishbein, M. An investigation of the relationships between beliefs about an object and the attitude toward that object. Hum. Relat. 1963, 16, 233-239. [CrossRef]

41. Fishbein, M.; Ajzen, I. Belief, Attitude, Intention and Behavior: An Introduction to Theory and Research; Addison-Wesley: Reading, UK, 1975; ISBN 978-0201020892.

42. Schepers, J.; Wetzels, M. A meta-analysis of the technology acceptance model: Investigating subjective norm and moderation effects. Inf. Manag. 2007, 44, 90-103. [CrossRef]

43. De Vries, H.; Dijkstra, M.; Kuhlman, P. Self-efficacy: The third factor besides attitude and subjective norm as a predictor of behavioural intentions. Health Educ. Res. 1988, 3, 273-282. [CrossRef]

44. Trafimow, D.; Fishbein, M. The moderating effect of behavior type on the subjective norm-behavior relationship. J. Soc. Psychol. 1994, 134, 755-763. [CrossRef]

45. Ajzen, I. Attitude structure and behavior. In Attitude Structure and Function; Pratkanis, A.R., Breckler, S.J., Greenwald, A.G., Eds.; Psychology Press: London, UK, 1989; pp. 241-274. ISBN 978-0805803235.

46. Ajzen, I. From intentions to actions: A theory of planned behavior. In Action Control; KuhlJürgen, J., Beckmann, J., Eds.; Springer: Berlin, Germany, 1985; pp. 11-39. ISBN 978-3-642-69746-3.

47. Ajzen, I.; Madden, T.J. Prediction of goal-directed behavior from attitudinal and normative variables. J. Exp. Soc. Psychol. 1986, 22, 453-474. [CrossRef]

48. Davis, F.D. Perceived usefulness, perceived ease of use, and user acceptance of information technology. MIS Q. 1989, 13, 319-340. [CrossRef]

49. Igbaria, M.; Schiffman, S.J.; Wieckowski, T.J. The respective roles of perceived usefulness and perceived fun in the acceptance of microcomputer technology. Behav. Inf. Technol. 1994, 13, 349-361. [CrossRef]

50. Lee, S.J.; Lina Kim, H. Roles of perceived behavioral control and self-efficacy to volunteer tourists' intended participation via theory of planned behavior. Int. J. Tour. Res. 2018, 20, 182-190. [CrossRef]

51. Maness, S.B.; Branscum, P. Utilizing a social determinant of health framework as determinants of perceived behavioral control. Fam. Community Health 2017, 40, 39-42. [CrossRef] [PubMed]

52. Cestac, J.; Paran, F.; Delhomme, P. Young drivers' sensation seeking, subjective norms, and perceived behavioral control and their roles in predicting speeding intention: How risk-taking motivations evolve with gender and driving experience. Saf. Sci. 2011, 49, 424-432. [CrossRef]

53. Kang, H.; Hahn, M.; Fortin, D.R.; Hyun, Y.J.; Eom, Y. Effects of perceived behavioral control on the consumer usage intention of e-coupons. Psychol. Mark. 2006, 23, 841-864. [CrossRef]

54. Kidwell, B.; Jewell, R.D. An examination of perceived behavioral control: Internal and external influences on intention. Psychol. Mark. 2003, 20, 625-642. [CrossRef]

55. Venkatesh, V. Determinants of perceived ease of use: Integrating perceived behavioral control, computer anxiety and enjoyment into the technology acceptance model. Inf. Syst. Res. 2000, 11, 342-365. [CrossRef] 
56. Manstead, A.S.; Eekelen, S.A. Distinguishing between perceived behavioral control and self-efficacy in the domain of academic achievement intentions and behaviors. J. Appl. Soc. Psychol. 1998, 28, 1375-1392. [CrossRef]

57. Sparks, P.; Guthrie, C.A.; Shepherd, R. The dimensional structure of the perceived behavioral control construct. J. Appl. Soc. Psychol. 1997, 27, 418-438. [CrossRef]

58. Godin, G.; Valois, P.; Lepage, L. The pattern of influence of perceived behavioral control upon exercising behavior: An application of Ajzen's theory of planned behavior. J. Behav. Med. 1993, 16, 81-102. [CrossRef] [PubMed]

59. James, W. The Principles of Psychology; Holt: New York, NY, USA, 1890; Volume 1, ISBN 9788459896093.

60. McDougall, W. Belief as a Derived Emotion. Psychol. Rev. 1921, 28, 315-327. [CrossRef]

61. Dashiell, J.F. A quantitative demonstration of animal drive. J. Comp. Psychol. 1925, 5, 205-208. [CrossRef]

62. Freud, A. Report of the twelfth international psycho-analytical congress. Bull. Int. Psycho-Anal. Assoc. 1933, 14, 138-180.

63. Aronoff, J. Freud's conception of the origin of curiosity. J. Psychol. 1962, 54, 39-45. [CrossRef]

64. Spielberger, C.D.; Starr, L.M. Curiosity and exploratory behavior. In Motivation: Theory and Research; O’Neil, H.F., Drillings, M., Eds.; Routledge: London, UK, 1994; pp. 221-243. ISBN 978-0805812862.

65. Webb, T.L.; Sheeran, P. Does changing behavioral intentions engender behavior change? A meta-analysis of the experimental evidence. Psychol. Bull. 2006, 132, 249-268. [CrossRef] [PubMed]

66. Triandis, H.C.; Brislin, R.W. Handbook of Cross-Cultural-Psychology; Allyn and Bacon: Boston, MA, USA, 1980; ISBN 978-0-20-5065011.

67. Sheeran, P. Intention-Behavior relations: A conceptual and empirical review. Eur. Rev. Soc. Psychol. 2002, 12, 1-36. [CrossRef]

68. Chatzisarantis, N.L.; Hagger, M.S. Mindfulness and the intention-behavior relationship within the theory of planned behavior. Personal. Soc. Psychol. Bull. 2007, 33, 663-676. [CrossRef] [PubMed]

69. Taylor, S.; Todd, P.A. Understanding information technology usage: A test of competing models. Inf. Syst. Res. 1995, 6, 144-176. [CrossRef]

70. Guo, Y.; Barnes, S.; Le-Nguyen, K. Consumer Acceptance IT Products: An Integrative Expectationconfirmation Model. In Proceeding of the Twenty-First Americas Conference on Information Systems, Fajardo, Puerto Rico, 13-15 August 2015.

71. Agarwal, R.; Karahanna, E. Time flies when you're having fun: Cognitive absorption and beliefs about information technology usage. MIS Q. 2000, 24, 665-694. [CrossRef]

72. Fu, H.; Ye, B.H.; Xiang, J. Reality TV, audience travel intentions, and destination image. Tour. Manag. 2016, 55, 37-48. [CrossRef]

73. De Cannière, M.H.; De Pelsmacker, P.; Geuens, M. Relationship quality and the theory of planned behavior models of behavioral intentions and purchase behavior. J. Bus. Res. 2009, 62, 82-92. [CrossRef]

74. Leung, S.O. A comparison of psychometric properties and normality in 4-, 5-, 6-, and 11-point Likert scales. J. Soc. Serv. Res. 2011, 37, 412-421. [CrossRef]

75. Tavakol, M.; Dennick, R. Making sense of Cronbach's alpha. Int. J. Med. Educ. 2011, 2, 53-55. [CrossRef] [PubMed]

76. Tabachnick, B.G.; Fidell, L.S. Using Multivariate Statistics; Allyn and Bacon: Boston, MA, USA, 2012; ISBN 978-0205849574.

77. Pett, M.A.; Lackey, N.R.; Sullivan, J.J. Making Sense of Factor Analysis: The Use of Factor Analysis for Instrument Development in Health Care Research; Sage: Thousand Oaks, CA, USA, 2003; ISBN 978-0761919506.

78. Crane, D.R.; Busby, D.M.; Larson, J.H. A factor analysis of the Dyadic Adjustment Scale with distressed and nondistressed couples. Am. J. Fam. Ther. 1991, 19, 60-66. [CrossRef]

79. Corbetta, P. Metodi di Analisi Multivariata per le Scienze Sociali. I Modelli di Equazioni Strutturali; Il Mulino: Bologna, Italy, 2002; ISBN 978-8815085016.

80. Brown, T. Confirmatory Factor Analysis for Applied Research; The Guilford Press: New York, NY, USA; London, UK, 2015; ISBN 978-1462515363.

81. Hu, L.T.; Bentler, P.M. Cutoff criteria for fit indexes in covariance structure analysis: Conventional criteria versus new alternatives. Struct. Equ. Model. Multidiscip. J. 1999, 6, 1-55. [CrossRef]

82. Ma, Y.J.; Gam, H.J.; Banning, J. Perceived ease of use and usefulness of sustainability labels on apparel products: Application of the technology acceptance model. Fash. Text. 2017, 4, 3-23. [CrossRef] 
83. Vermeir, I.; Verbeke, W. Sustainable food consumption: Exploring the consumer "attitude-behavioral intention" gap. J. Agric. Environ. Ethics 2006, 19, 169-194. [CrossRef]

84. Tanner, C.; Wölfing Kast, S. Promoting sustainable consumption: Determinants of green purchases by Swiss consumers. Psychol. Mark. 2003, 20, 883-902. [CrossRef]

85. Bissonnette, M.M.; Contento, I.R. Adolescents' perspectives and food choice behaviors in terms of the environmental impacts of food production practices: Application of a psychosocial model. J. Nutr. Educ. 2001, 33, 72-82. [CrossRef]

86. Chan, R.Y. Determinants of Chinese consumers' green purchase behavior. Psychol. Mark. 2001, 18, $389-413$. [CrossRef]

87. Barr, S. Strategies for sustainability: Citizens and responsible environmental behaviour. Area 2003, 35, 227-240. [CrossRef]

88. Fielding, K.S.; Terry, D.J.; Masser, B.M.; Hogg, M.A. Integrating social identity theory and the theory of planned behaviour to explain decisions to engage in sustainable agricultural practices. Br. J. Soc. Psychol. 2008, 47, 23-48. [CrossRef] [PubMed]

89. Glanz, K.; Rimer, B.K.; Viswanath, K. Health Behavior and Health Education: Theory, Research, and Practice; John Wiley \& Sons: Hoboken, NJ, USA, 2008; ISBN 978-0-787-99614-7.

90. Robinson, R.; Smith, C. Psychosocial and demographic variables associated with consumer intention to purchase sustainably produced foods as defined by the Midwest Food Alliance. J. Nutr. Educ. Behav. 2002, 34, 316-325. [CrossRef]

91. Kashdan, T.B.; Steger, M.F. Curiosity and pathways to well-being and meaning in life: Traits, states, and everyday behaviors. Motiv. Emot. 2007, 31, 159-173. [CrossRef]

92. Clark, W.C. Sustainability science: A room of its own. Proc. Natl. Acad. Sci. USA 2007, 104, 1737-1745. [CrossRef] [PubMed]

93. Tapia-Fonllem, C.; Corral-Verdugo, V.; Fraijo-Sing, B.; Durón-Ramos, M.F. Assessing sustainable behavior and its correlates: A measure of pro-ecological, frugal, altruistic and equitable actions. Sustainability 2013, 5, 711-723. [CrossRef]

94. Ciasullo, M.V.; Cardinali, S.; Cosimato, S. A strenuous path for sustainable supply chains in the footwear industry: A business strategy issue. J. Glob. Fash. Mark. 2017, 8, 143-162. [CrossRef]

95. Ciasullo, M.V.; Cardinali, S.; Cosimato, S. Exploring sustainable behaviour in international footwear supply chain management. Int. J. Bus. Glob. 2018, 20, 416-436. [CrossRef] 